\title{
Composition Dependence and Optical Properties of Polymethyl Methacrylate/Alumina Nanocomposite in the IR Region Determined by Kramers-Kronig Relation
}

\author{
Misagh Ghamari ${ }^{\dagger}$ and Mahdi Ghasemifard \\ Nano Technology Laboratory, Esfarayen University of Technology, Esfarayen 98195-96619, Iran \\ (Received July 10, 2016; Revised January 18, 2017; Accepted January 19, 2017)
}

\begin{abstract}
The dependence of the IR optical properties of $\mathrm{PMMA} / \mathrm{Al}_{2} \mathrm{O}_{3}$ nanocomposite on the alumina content was investigated in the wavelength range of $3500-2800 \mathrm{~cm}^{-1}$. The samples were prepared via emulsion polymerization technique using oleic acid as a coupling agent. Grafting density calculations were carried out by means of elemental analysis CHN to yield the best coupling agent content. FTIR analysis confirmed the existence of a chemical bond between aluminum oxide and oleic acid. The outcomes of XRD analyses showed the presence of cubic gamma aluminum oxide in the nanocomposite, in contrast to the amorphous nature of PMMA. TEM images showed the core-shell morphology of the particles other than pristine PMMA. Optical constants of the nanocomposite were calculated based on FTIR spectra and the Kramers-Kronig equations. The presence of nano alumina modified some of the optical indexes in IR region.
\end{abstract}

Key words : Alumina, Kramers-Kronig, Grafting density, Refractive index

\section{Introduction}

$\mathrm{T}$ he Kramers-Kronig (KK) technique has been used to evaluate the reflection spectra to determine a number of optical parameters of materials. ${ }^{1-5)}$ This may be because this technique is easier to develop and can be applied to scrutinize a wide variety of materials without reference to detailed models. There has been great interest in the KK technique for the evaluation of the IR reflectance spectra of several materials. These spectra are determined by the broadly used Fourier transforms infrared (FTIR) spectroscopy.

Ceramics are common materials used to improve certain physical and mechanical properties of polymers such as the hardness, Young's modulus, creep resistance and thermal stability. ${ }^{6)}$ Although many studies have been carried out to investigate the effects of ceramics on mechanical properties, optical features as well may change when using ceramic materials in the polymer matrix. ${ }^{7,8)}$ Polymethyl methacrylate (PMMA) is one of the most important acrylates due to its exceptional optical clarity ${ }^{9)}$ and mechanical properties. ${ }^{10)}$ It is possible to change some of the optical constants of polymers in a number of frequencies by using a proper ceramic as a filler. Aluminum oxide, or alumina, is a valuable ceramic material due to its prominent mechanical, thermal, optical, and chemical properties, which provide new opportunities for applications as both bulk and filler. ${ }^{711-17)}$ By

Corresponding author: Misagh Ghamari

E-mail : Ghamari_iust@yahoo.com

Tel : +98-58-3726-6538 Fax : +98-58-3726-6539 using alumina as a filler, the physical and mechanical properties of polymers can change, but, first, the surface must be sufficiently modified ${ }^{18)}$ so as to be able to bond suitably to the polymer chains. Sufficient information about the content of the coupling agent necessary for acceptable surface modification is necessary to reach the best grafting of the coupling agent to the surface of the alumina nanoparticles. Grafting density and grafting yield will be calculated by using CHN elemental analysis which is a scientific instrument that can determine the elemental concentrations in a given sample and is used to measure Carbon (C), Hydrogen $(\mathrm{H})$ and Nitrogen $(\mathrm{N})$. The purpose of the present study is to develop a Kramers-Kronig exploration to analyze the infrared (IR) reflectance spectra from FTIR spectroscopy results for nanocomposites prepared by emulsion polymerization. The samples were characterized by means of FTIR, XRD, CHN, and TEM; finally, the phase change of the incident wave, the refractive index (real and imaginary), and the complex dielectric function were calculated in the wavelength range of $3500-2800 \mathrm{~cm}^{-1}$; the composition dependence of the optical features is discussed.

\section{Experimental Procedure}

\subsection{Materials}

In this study, the following materials were used as received without further purification. Methyl methacrylate $\left(100.12 \mathrm{~g} \cdot \mathrm{mol}^{-1}\right)$, Oleic acid $\left(282.46 \mathrm{~g} \cdot \mathrm{mol}^{-1}\right)$, sodium dodecyl sulfate (SDS $288.372 \mathrm{~g} / \mathrm{mol}$ ), ammonium persulfate (APS $228.2 \mathrm{~g} / \mathrm{mol}$ ), and ammonia solution (25\%), all from Merck, and alumina nanoparticles from Scharlo, were used. 


\subsection{Characterization}

FTIR characterization of the nanocomposite materials was accomplished using a Shimadzu (8400S) Fourier Transform infrared spectrophotometer. FTIR spectra were measured in the range of $400-4000 \mathrm{~cm}^{-1}$ with $\mathrm{KBr}$. TEM analysis was performed with a PHILIPS microscope (accelerating voltage of $80 \mathrm{kV}$ ). XRD experiments were carried out using an XRD PHILIPS model PW1800. Finally, CHN elemental analysis was conducted by means of a Costech ECS 4010.

\subsection{Nanocomposite Synthesis}

In a typical procedure, first, the alumina nanoparticles were vacuum dried at $100^{\circ} \mathrm{C}$ to eliminate water. Then, using a proper $\mathrm{OA} / \mathrm{Al}_{2} \mathrm{O}_{3}$ ratio, the surface of the alumina nanoparticles was modified by exposure under vigorous stirring to an $\mathrm{OA} /$ toluene solution at $50^{\circ} \mathrm{C}$ for $12 \mathrm{~h}$. After surface modification of the $\mathrm{Al}_{2} \mathrm{O}_{3}$ particles, particles were dried again at $80^{\circ} \mathrm{C}$ for $5 \mathrm{~h}$. The surface modified alumina particles (SMA) were then dispersed in methyl methacrylate (MMA) using an ultrasonic apparatus. Emulsification of the monomer-SMA mixture was performed using an aqueous solution of sodium dodecyl sulfate. Finally, emulsion polymerization was carried out at $80^{\circ} \mathrm{C}$ by adding ammonium persulfate as an initiator under a nitrogen stream for $3 \mathrm{~h}$. The process was done for PMMA (without alumina), PMMA/ $15 \mathrm{Al}_{2} \mathrm{O}_{3}(\mathrm{P} 15 \mathrm{~A})$, and $\mathrm{PMMA} / 25 \mathrm{Al}_{2} \mathrm{O}_{3}(\mathrm{P} 25 \mathrm{~A})$.

\section{Results and Discussion}

\subsection{Grafting density calculations}

Diverse $\mathrm{OA} / \mathrm{Al}_{2} \mathrm{O}_{3}$ ratios were utilized in order to allow a choice of the highest grafting yield as the main composition. Based on the results of the CHN analysis, the carbon content difference of alumina and oleic acid grafted alumina after surface modification can be attained. The existence of carbon on the alumina nanoparticles after modification is due to surface modification with oleic acid. Furthermore, grafting density (GD) can be calculated from the following equation $^{19)}$ :

$$
\text { Grafting density }\left(\frac{\mu \mathrm{mol}}{\mathrm{m}^{2}}\right)=\frac{10^{6} \Delta C}{[(1200 N c-\Delta C(M-1)) S]}
$$

where $\Delta C$ is the carbon difference between alumina before and after modification, $N c$ and $\mathrm{M}$ are the number of carbon atoms and the molar mass of oleic acid, and $\mathrm{S}$ is the surface area of the nano alumina particles $\left(\mathrm{m}^{2} / \mathrm{g}\right)$. The grafting yield, which corresponds to the fraction of OA grafted onto alumina, can be calculated using the following equation:

$$
\text { Grafting yield }(\%)=\frac{\text { grafting density }}{\text { [Oleic acid }]} \times 100
$$

where [Oleic acid] $\left(\mu \mathrm{mol} \cdot \mathrm{m}^{-2}\right)$ is the initial concentration of OA. The outcomes of the grafting density and the grafting yield are shown in Table 1.

As can be seen, the maximum grafting yield for $\mathrm{OA} / \mathrm{Al}_{2} \mathrm{O}_{3}$ $=1.5$ is 2.018094 . Therefore, this ratio was used to prepare
Table 1. Grafting Density and Grafting Yield of Different OA/ Alumina Ratios

\begin{tabular}{ccccc}
\hline $\begin{array}{c}\mathrm{OA} / \mathrm{Al}_{2} \mathrm{O}_{3} \\
\text { ratio } \\
\text { (mass) }\end{array}$ & $\begin{array}{c}{[\mathrm{OA}]} \\
\left(\frac{\mu \mathrm{mol}}{\mathrm{m}^{2}}\right)\end{array}$ & $\begin{array}{c}\text { Carbon } \\
\text { difference }\end{array}$ & $\begin{array}{c}\text { Grafting } \\
\text { density } \\
\left(\frac{\mu \mathrm{mol}}{\mathrm{m}^{2}}\right)\end{array}$ & $\begin{array}{c}\text { Grafting } \\
\text { yield } \\
(\%)\end{array}$ \\
\hline 0.5 & 25.288 & 0.5813 & 0.387392 & 1.53192 \\
1.0 & 50.576 & 1.4274 & 0.96194 & 1.901968 \\
1.5 & 75.864 & 2.2471 & 1.531007 & 2.018094 \\
2.0 & 101.152 & 2.3104 & 1.575473 & 1.55753 \\
\hline
\end{tabular}

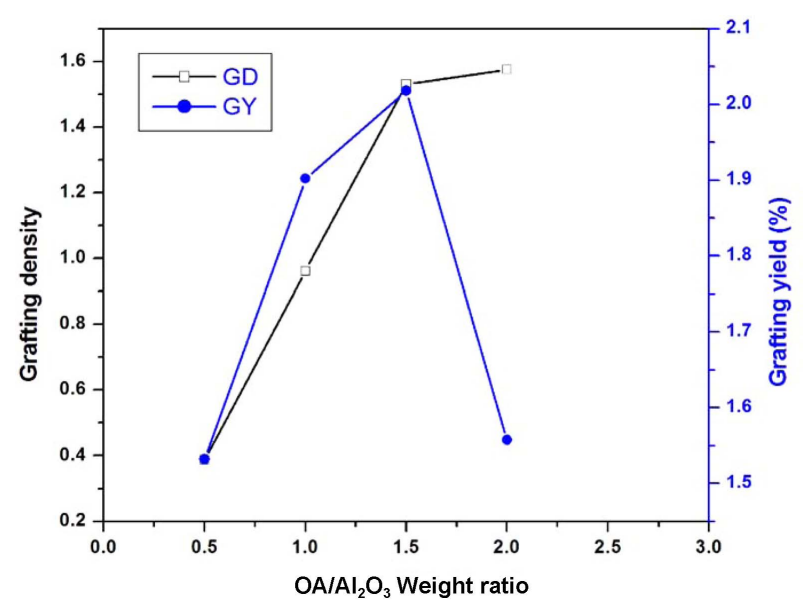

Fig. 1. Variations of GD and GY vs. $\mathrm{OA} / \mathrm{Al}_{2} \mathrm{O}_{3}$ weight ratio.

the nanocomposites. The variations of GD and GY with the $\mathrm{OA} / \mathrm{Al}_{2} \mathrm{O}_{3}$ weight ratio are shown in Fig. 1 . There is a growing trend in GD and GY with increasing of the $\mathrm{OA} / \mathrm{Al}_{2} \mathrm{O}_{3}$ ratio up to 1.5; the maximum value of GY is reached, and then GY diminishes abruptly, while GD increases slightly with increasing of the $\mathrm{OA} / \mathrm{Al}_{2} \mathrm{O}_{3}$ ratio to 2 .

\subsection{FTIR analysis}

Infrared spectroscopy is used for exploration of the structural configuration of materials, especially those including

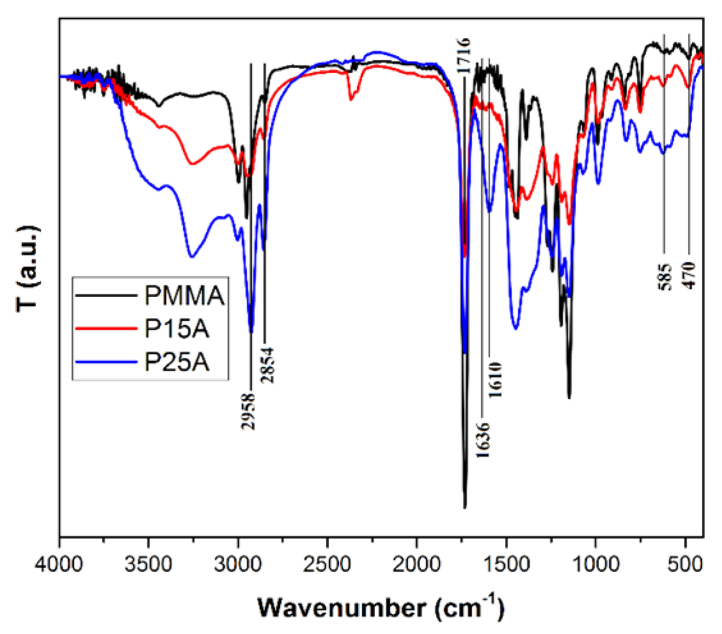

Fig. 2. FTIR of pure PMMA, P15A, and P25A. 
organic compounds, because of its proper sensitivity to infrared energy.

Figure 2 displays FT-IR spectra of PMMA and P15A, and $\mathrm{P} 25 \mathrm{~A}$. The disappearance of the peak at $1636 \mathrm{~cm}^{-1}$ related to the $\mathrm{C}=\mathrm{C}$ bond can be the result of good monomer conversion. There is a sharp peak at $1716 \mathrm{~cm}^{-1}$; this peak is associated with a carbonyl group $(\mathrm{C}=\mathrm{O})$ that is present in all samples because this bond does not change during polymerization. Stretch vibrations of the methyl groups are recognized as having a frequency of $2958 \mathrm{~cm}^{-1}$; this frequency is relatively stronger in the first sample (PMMA), while for the other samples it is broadened because of the formation of aluminum oleate. The existence of a bond between the aluminum ions and the carboxylate groups of oleic acid is confirmed by the $1610 \mathrm{~cm}^{-1}$ band, which cannot be seen in the pristine polymer. Since oleic acid contains a lot of $\mathrm{CH}_{2}$ groups, there must be an intensive peak associated with them in P15A and P25A. The peak at $2854 \mathrm{~cm}^{-1}$ in PMMA is weaker than those of P15A and P25A, which is the existence of oleic acid in the composite. Peaks below $1000 \mathrm{~cm}^{-1}$ correspond to $\mathrm{Al}-\mathrm{O}$ stretching absorption; these include vibrations at $585 \mathrm{~cm}^{-1}$ and $470 \mathrm{~cm}^{-1}$, which are attributed to the vibrational stretching of the Al-O octahedral groups. ${ }^{20,21)}$ In general, due to the incorporation of inorganic components, the absorption peaks of PMMA in organic groups are stronger than those in the nanocomposite.

\subsection{XRD investigation}

Powder X-ray diffraction (XRD) patterns of PMMA and

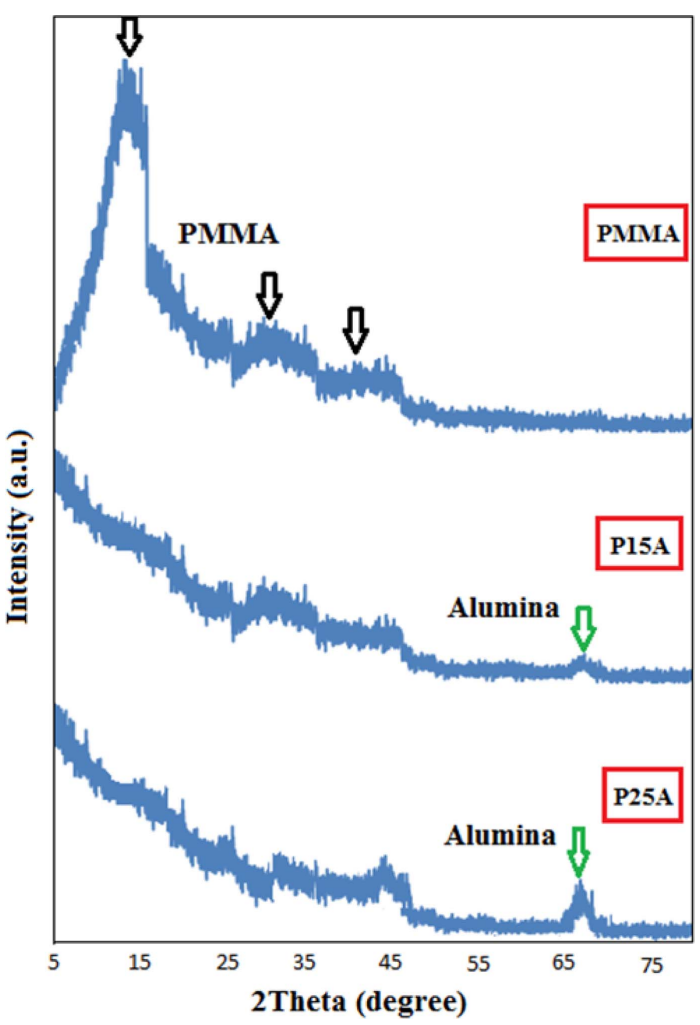

Fig. 3. XRD patterns of PMMA, P15A, and P25A.
PMMA $/ \mathrm{Al}_{2} \mathrm{O}_{3}$ nanocomposites (P15A and P25A) are plotted in Fig. 3. Generally, the powder X-ray diffraction patterns in amorphous systems show broadened peaks, as can be seen for PMMA, which is entirely amorphous; consequently, according to JCPDS Card no. 13-0835, the diffraction pattern of PMMA shows the most intense peaks at 2 theta values of $13^{\circ}, 27^{\circ}$, and $41^{\circ}$. A comparison of the spectra of PMMA and PMMA $/ \mathrm{Al}_{2} \mathrm{O}_{3}$ shows different behavior for the two materials.

It was observed that the intensity of the diffraction peaks in pristine PMMA meaningfully decreased as a result of alumina incorporation. In addition, the presence of new peaks was detected by the presence of alumina, as expected. The peak at $65^{\circ}$ shows the presence of gamma alumina with cubic structure. An increasing crystallinity of $\mathrm{PMMA} / \mathrm{Al}_{2} \mathrm{O}_{3}$ is observed with increase of the alumina content from 15 to $25 \%$ in terms of mass. The nano nature of samples was clear from the broadening peaks.

\subsection{TEM investigation}

Figure 4 shows the TEM images of PMMA, P15A, and P25A. Bonding between hydrophilic alumina and hydrophobic PMMA was created by means of the coupling agent oleic acid. The surface of the alumina nanoparticles was modified before polymerization; then, the surface modified particles were mixed with MMA and polymerization occurred.

It can be clearly observed that, because of the particles tendency to bond to each other, increasing the alumina content from 15 to $25 \%$ wt in the nanocomposite results in the appearance of agglomerates of alumina particles. The size of the fillers remained almost constant when the polymer shape was changed from spherical in the pure state to a shell-like round filler. Before polymerization, the surface of the particles was modified with oleic acid, which induces a $\mathrm{C}=\mathrm{C}$ bond on the surface of alumina particles. During polymerization, this double bond can open and polymerization can take place on the surface of the fillers. Therefore, the above (Fig. 4) morphology for the nanocomposites can be achieved. It is possible to create a polymer shell around the filler particles, provided that sufficient coupling agents can

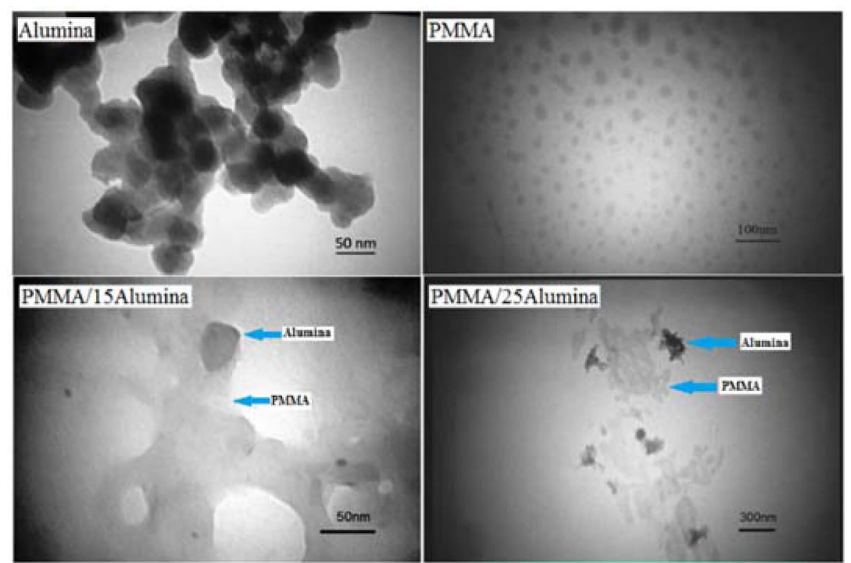

Fig. 4. TEM images of PMMA, P15A, and P25A. 
bond to the surface of the inorganic constituents.

\subsection{Optical constants determine by Kramers-Kronig analysis}

According to the FTIR spectra and the following relations, some of the optical constants of the nanocomposites were calculated for a film of which the thickness is $70 \mu \mathrm{m}$. In order to use the Kramers-Kronig relation, the first reflection spectra of the samples must be withdrawn.

$$
\begin{aligned}
& A=2-\log (T) \\
& R=100-T-A
\end{aligned}
$$

The phase change $\varphi$ at a particular frequency between the incidence and the reflected wave is acquired from the KK dispersion relation: ${ }^{22)}$

$$
\varphi(w)=-\frac{w}{\pi} \int_{0}^{\infty} \frac{\operatorname{Ln} R\left(\dot{w}^{\prime}\right)-\operatorname{Ln} R(w)}{\dot{w}^{2}-w^{2}} d(\dot{w})
$$

The spectrum of $\varphi(w)$ is used to obtain the real (n) and imaginary $(\mathrm{k})$ parts of the complex refractive index, according to the following equations: ${ }^{23)}$

$$
\begin{aligned}
& n=\frac{1-R(w)}{(1+R(w))-2 \sqrt{R(w)} \cos \varphi(w)} \\
& k=\frac{2 \sqrt{R(w)} \sin \varphi(w)}{(1+R(w))-2 \sqrt{R(w)} \cos \varphi(w)}
\end{aligned}
$$

Based on Eqs. (3) and (4), simulated IR reflectivity spectra for nanocomposites were derived. The reflection of the samples in the range of $3500-2800 \mathrm{~cm}^{-1}$ is shown in Fig. 5 .

As can be seen in Fig. 5, the reflection of IR in the range of $3500-2800 \mathrm{~cm}^{-1}$ has been increased; four peaks for reflection are obvious. The peaks at about $3250 \mathrm{~cm}^{-1}$ are assigned to hydroxyl groups on the surface of the aluminum oxide. Based on the reflection, and according to Eq. (3), the phase change of the incident wave across the nanocomposite versus the wavenumber in the range of $3500-2800 \mathrm{~cm}^{-1}$ is plot-

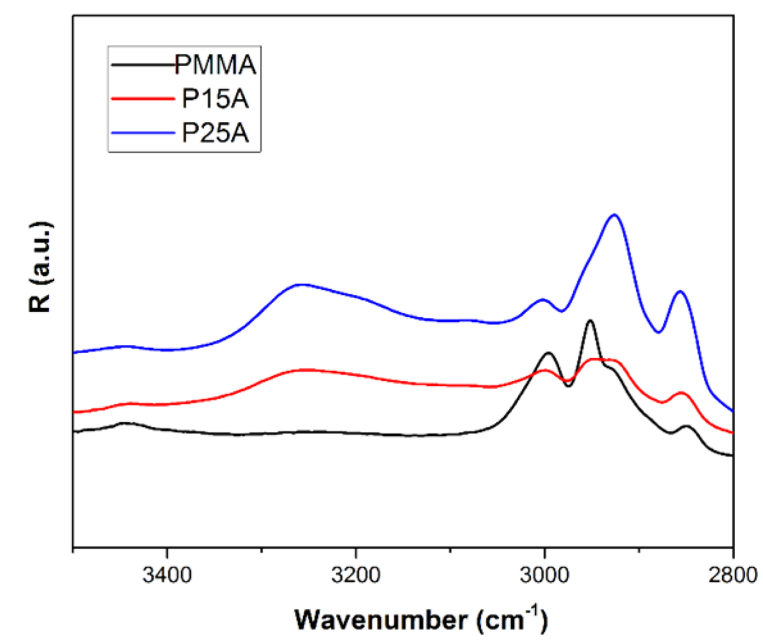

Fig. 5. Reflection spectra of nanocomposites in range of 3500 $-2800 \mathrm{~cm}^{-1}$.

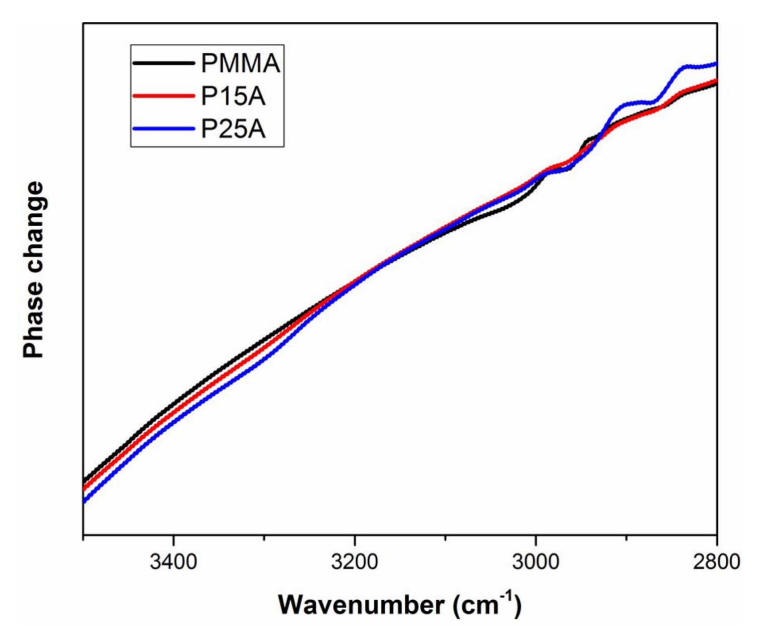

Fig. 6. Phase change vs. wavenumber in range of $3500-2800$ $\mathrm{cm}^{-1}$.

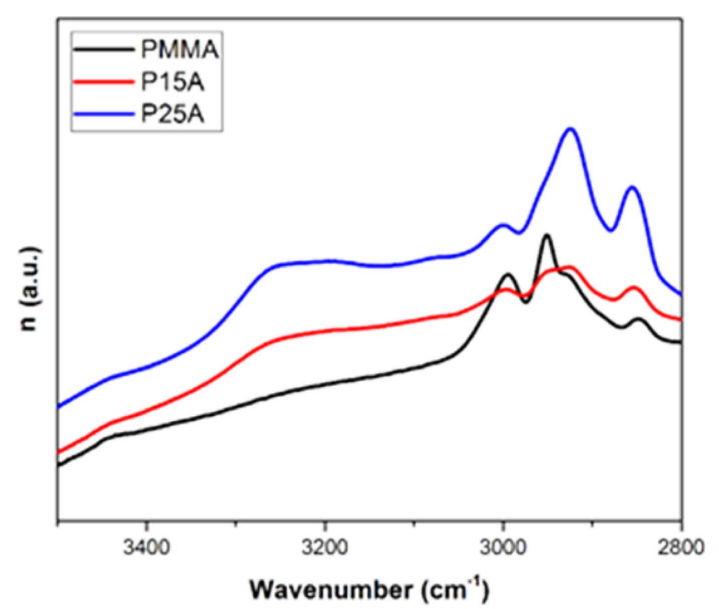

Fig. 7. Real part of refractive index of nanocomposites in range of $3500-2800 \mathrm{~cm}^{-1}$.

ted in Fig. 6.

The total trend for samples is the same, except that in the vicinity of $2950-2850 \mathrm{~cm}^{-1}$ the impact of aluminum oxide on the behavior of the graph is remarkable.

Based on the spectra of $\mathrm{R}(\mathrm{w})$ and $\varphi(\mathrm{w})$, the spectra of $\mathrm{n}(\mathrm{w})$, $\mathrm{k}(\mathrm{w}), \varepsilon_{1}(w)$, and $\varepsilon_{2}(w)$ were obtained by numerical calculations.

The real and imaginary parts of the refractive index are plotted in Fig. 7 and Fig. 8 in the range of $3500-2800 \mathrm{~cm}^{-1}$.

According to Fig. 8, the values of the imaginary part of the refractive index become higher with increasing alumina content for wavenumbers higher than $2850 \mathrm{~cm}^{-1}$; this may be due to excess hydroxyl groups in the alumina composites.

Subsequently, the real $\left(\varepsilon_{1}\right)$ and imaginary $\left(\varepsilon_{2}\right)$ parts of the complex dielectric function can be obtained by using:

$$
\begin{aligned}
& \varepsilon_{1}=n^{2}-k^{2} \\
& \varepsilon_{2}=2 n k
\end{aligned}
$$

Figures 9 and 10 illustrate the real and imaginary parts of 


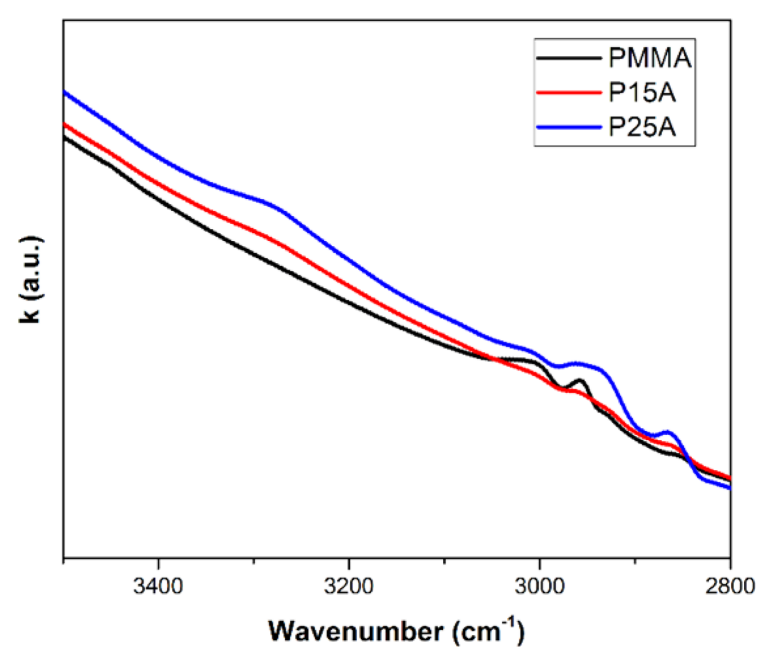

Fig. 8. Imaginary part of refractive index of nanocomposites in range of $3500-2800 \mathrm{~cm}^{-1}$.

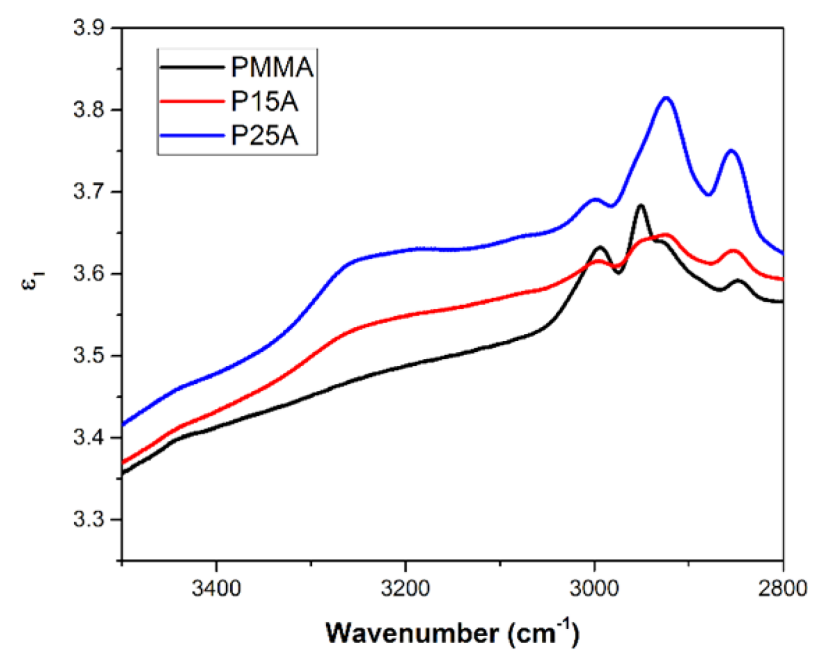

Fig. 9. Spectrum of the real part of the dielectric function for nanocomposites.

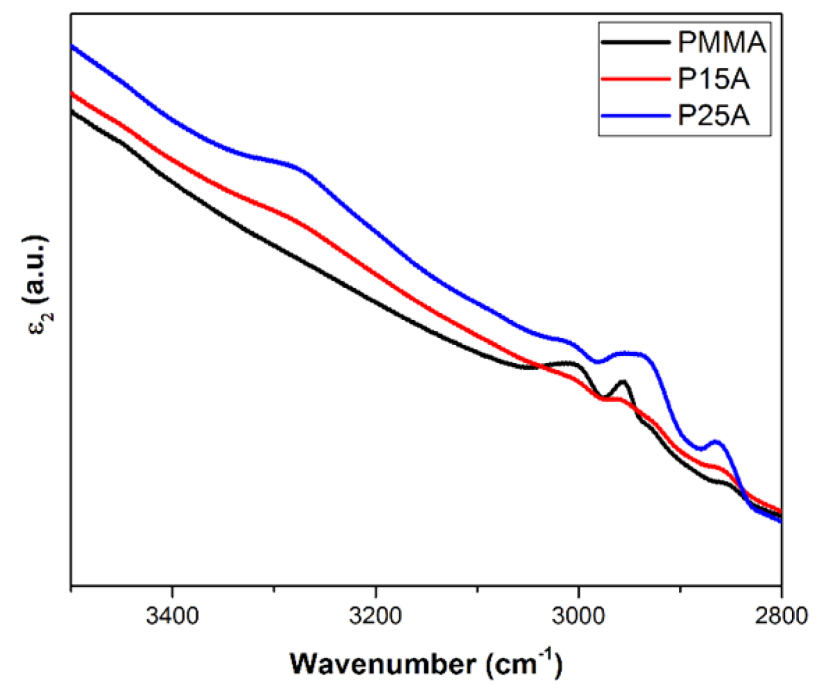

Fig. 10. Imaginary part of the dielectric function for nanocomposites. the dielectric function versus the wavenumber in the range of $3500-2800 \mathrm{~cm}^{-1}$.

Regarding the fact that alumina dielectric constant is higher than PMMA, and based on Figs. 9 and 10, the real and imaginary parts of the dielectric function can be said to have increased with increasing alumina at normal incidence in the range of $3500-2800 \mathrm{~cm}^{-1}$.

\section{Conclusions}

In order to explore their optical constants, $\mathrm{PMMA} / \mathrm{Al}_{2} \mathrm{O}_{3}$ nanocomposites were successfully prepared by emulsion polymerization with different amounts of alumina nanoparticles. The results of FTIR showed the presence of a chemical bond between PMMA and alumina. The existence of cubic gamma alumina was revealed by XRD. Increasing the filler content from $15 \%$ to $25 \%$ was found to result in agglomeration of the particles, which was confirmed by TEM images. We have offered a detailed explanation of the use of the Kramers-Kronig (KK) technique to examine normal incidence infrared (IR) reflectance spectra. In addition, KK was used to extract the optical constants, such as the complex refractive index and complex dielectric constants, by mathematical calculation.

\section{REFERENCES}

1. D. M. Roessler, "Kramers-Kronig Analysis of Reflection Data," Br. J. Appl. Phys., 16 [8] 1119 (1965).

2. M. R. Querry, R. C. Waring, W. E. Holland, G. M. Hale, and W. Nijm, "Optical Constants in the Infrared for Aqueous Solutions of NaCl," JOSA, 62 [7] 849-55 (1972).

3. R. Bauer, W. Spicer, and J. J. White, "Investigation of the Kramers-Kronig Analysis: Revised Optical Constants of AgCl," JOSA, 64 [6] 830-33 (1974).

4. L. Didrikil, "Determination of the Optical Constants of Condensed Media from the Reflectance Spectra of Nonpolarized or Partly Polarized Light at an Oblique Angle of Incidence Using Kramers-Kronig Method," Opt. Spectrosc., 38 202-5 (1975).

5. K. Yamamoto and A. Masui, "Complex Refractive Index Determination of Bulk Materials from Infrared Reflection Spectra," Appl. Spectrosc., 49 [5] 639-44 (1995).

6. P. M. Ajayan, L. S. Schadler, and P. V. Braun, Nanocomposite Science and Technology; pp. 77-95, John Wiley \& Sons, Weinheim, 2006.

7. S. Mallakpour and E. Khadem, "Recent Development in the Synthesis of Polymer Nanocomposites Based on NanoAlumina," Prog. Polym. Sci., 51 74-93 (2015).

8. A. Kadian, S. Arora, A. Sharma, G. M. Joshi, M. Pandey, A. P. Reddy, M. Joshi, and P. Thomas, "Improved Dielectric Constant of Thermoplastic Blend as a Function of Alumina Loading," Measurement, 90 461-67 (2016).

9. K. Peters, "Polymer Optical Fiber Sensors-A Review," Smart Mater. Struct., 20 [1] 013002 (2010).

10. J. Jordan, D. Casem, P. Moy, and T. Walter, "Mechanical Properties and Shock Response of PMMA," Bull. Am. Phys. Soc., 60 (2015). 
11. F. A. Alzarrug, M. M. Dimitrijević, R. M. J. Heinemann, V. Radojević, D. B. Stojanović, P. S. Uskoković, and R. Aleksić, "The Use of Different Alumina Fillers for Improvement of the Mechanical Properties of Hybrid PMMA Composites," Mater. Des., 86 575-81 (2015).

12. B. J. Ash, R. W. Siegel, and L. S. Schadler, "Glass-Transition Temperature Behavior of Alumina/PMMA Nanocomposites," J. Polym. Sci., Part B: Polym. Phys., 42 [23] 437183 (2004).

13. D. L. Burris and W. G. Sawyer, "Improved Wear Resistance in Alumina-PTFE Nanocomposites with Irregular Shaped Nanoparticles," Wear, 260 [7] 915-18 (2006).

14. Z. Guo, T. Pereira, O. Choi, Y. Wang, and H. T. Hahn, "Surface Functionalized Alumina Nanoparticle Filled Polymeric Nanocomposites with Enhanced Mechanical Properties," J. Mater. Chem., 16 [27] 2800-8 (2006).

15. B.-Y. Kim, Y. Lee, S.-R. Kim, D.-G. Shin, W.-T. Kwon, D.-K. Choi, and Y. Kim, "Asperities on the Surface of Plate-like Alumina and their Effect on Nacre-inspired Alumina-PMMA Composites," J. Korean Ceram. Soc., 52 [4] 248-52 (2015).

16. K. M. Nam, Y. J. Lee, W. T. Kwon, S. R. Kim, H. M. Lim, H. Kim, and Y. Kim, "Preparation of $\mathrm{Al}_{2} \mathrm{O}_{3}$ Platelet/PMMA Composite and Its Mechanical/Therml Characterization," J. Korean Ceram. Soc., 49 [5] 438-41 (2012).

17. B.-T. Lee, D. V. Quang, and H.-Y. Song, "Fabrication of Porous
$\mathrm{Al}_{2} \mathrm{O}_{3}-\left(\mathrm{m}-\mathrm{ZrO}_{2}\right)$ Composites and $\mathrm{Al}_{2} \mathrm{O}_{3}-\left(\mathrm{m}-\mathrm{ZrO}_{2}\right) / \mathrm{PMMA}$ Hybrid Composites by Infiltration Process," J. Korean Ceram. Soc., 44 [6] 291-96 (2007).

18. N. Cinausero, N. Azema, M. Cochez, M. Ferriol, M. Essahli, F. Ganachaud, and J. M. Lopez-Cuesta, "Influence of the Surface Modification of Alumina Nanoparticles on the Thermal Stability and Fire Reaction of PMMA Composites," Polym. Adv. Technol., 19 [6] 701-9 (2008).

19. G. E. Berendsen and L. D. Galan, "Preparation and Chromatographic Properties of Some Chemically Bonded Phases for Reversed-Phase Liquid Chromatography," J. Liq. Chromatogr., 1 [5] 561-586 (1978).

20. L. Wu, Y. Huang, Z. Wang, L. Liu, and H. Xu, "Fabrication of Hydrophobic Alumina Aerogel Monoliths by Surface Modification and Ambient Pressure Drying," Appl. Surf. Sci., 256 [20] 5973-77 (2010).

21. P. Colomban, "Raman Study of the Formation of Transition Alumina Single Crystal from Protonic $\beta / \beta$ " Aluminas," $J$. Mater. Sci. Lett., 7 [12] 1324-26 (1988).

22. F. Stern, "Elementary Theory of the Optical Properties of Solids," Solid State Phys., 15 299-408 (1963).

23. M. Ghasemifard, E. Fathi, and M. Ghamari, "The Effect of $\mathrm{Fe}^{3+}$-Doped on Structure and Optical Properties of Mesoporous $\mathrm{Al}_{2} \mathrm{O}_{3} / \mathrm{SiO}_{2}$ Composite," Mater. Sci. Semicond. Process., 42 349-53 (2016). 